\title{
Hormonal crises following receptor radionuclide therapy with the radiolabeled somatostatin analogue $\left[{ }^{177}\right.$ Lu-DOTA ${ }^{0}$, Tyr $\left.^{3}\right]$ octreotate
}

\author{
Bart de Keizer • Maarten O. van Aken • \\ Richard A. Feelders - Wouter W. de Herder • \\ Boen L. R. Kam • Martijn van Essen • \\ Eric P. Krenning • Dik J. Kwekkeboom
}

Received: 12 November 2007 / Accepted: 14 December 2007 / Published online: 16 January 2008

(C) The Author(s) 2007

\begin{abstract}
Introduction Receptor radionuclide therapy is a promising treatment modality for patients with neuroendocrine tumors for whom alternative treatments are limited. The aim of this study was to investigate the incidence of hormonal crises after therapy with the radiolabeled somatostatin analogue $\left[{ }^{177}\right.$ Lu-DOTA $\left.{ }^{0}, \mathrm{Tyr}^{3}\right]$ octreotate $\left({ }^{177}\right.$ Lu-octreotate) .

Materials and methods All ${ }^{177} \mathrm{Lu}-\mathrm{octreotate}$ treatments between January 2000 and January 2007 were investigated. Four hundred seventy-six patients with gastroenteropancreatic neuroendocrine tumors and three patients with metastatic pheochromocytoma were included for analysis.

Results Four hundred seventy-nine patients received a total of 1,693 administrations of ${ }^{177} \mathrm{Lu}$-octreotate. Six of 479 patients $(1 \%)$ developed severe symptoms because of massive release of bioactive substances after the first cycle of ${ }^{177} \mathrm{Lu}$-octreotate. One patient had a metastatic hormoneproducing small intestinal carcinoid; two patients had metastatic, hormone-producing bronchial carcinoids; two patients had vasoactive intestinal polypeptide-producing pancreatic endocrine tumors (VIPomas); and one patient had a metastatic pheochromocytoma. With adequate treatment, all patients eventually recovered.
\end{abstract}

B. de Keizer $(\bowtie) \cdot$ B. L. R. Kam • M. van Essen

E. P. Krenning • D. J. Kwekkeboom

Department of Nuclear Medicine, Erasmus Medical Center,

Rotterdam, P.O. Box 2040, 3000 CA, The Netherlands

e-mail: b.dekeizer@erasmusmc.nl

M. O. van Aken • R. A. Feelders $\cdot$ W. W. de Herder

Section of Endocrinology, Department of Internal Medicine,

Erasmus Medical Center,

Rotterdam, The Netherlands
Conclusion Hormonal crises after ${ }^{177} \mathrm{Lu}$-octreotate therapy occur in $1 \%$ of patients. Generally, ${ }^{177} \mathrm{Lu}$-octreotate therapy is well tolerated.

Keywords Lu-177-octreotate - Neuroendocrine tumors . Peptide receptor radionuclide therapy $\cdot$ Carcinoid crisis

\section{Introduction}

Gastroenteropancreatic neuroendocrine tumors (GEPNETs) constitute a heterogeneous group of neoplasms. Two major GEPNET subcategories are intestinal endocrine tumors or carcinoids and pancreatic neuroendocrine tumors (PNETs). These tumors are often slow growing and may be associated with typical symptoms because of excessive and uncontrolled release of various metabolically active amines and peptides, such as serotonin, gastrin, glucagon, somatostatin, insulin, vasoactive intestinal polypeptide (VIP), and substance P. Pheochromocytomas are catecholamine-producing tumors, which generally arise in the adrenal medulla.

A so-called carcinoid crisis is a medical emergency caused by the excessive release of metabolically active amines or peptides that can occur spontaneously after manipulation of a carcinoid tumor, during induction of anesthesia, during surgery, endoscopy, or with chemotherapy [1-5]. The symptomatology involves profound flushing, hypotension, or extreme changes in blood pressure, diarrhea, bronchoconstriction, and arrhythmias [6]. So far, only one case of a carcinoid crisis after therapy with a radiolabeled somatostatin analogue has been described [7]. Another well-recognized endocrine emergency can occur in patients with pheochromocytomas. This is caused by the 
massive release of catecholamines, which can occur spontaneously, after manipulation of the tumor or during medical interventions [8].

Since the year 2000, patients with somatostatin receptorpositive metastatic, inoperable GEPNETs and malignant pheochromocytomas have been treated with the radiolabeled somatostatin analogue $\left[{ }^{177} \mathrm{Lu}^{-D O T A}{ }^{0}, \mathrm{Tyr}^{3}\right]$ octreotate $\left({ }^{177} \mathrm{Lu}\right.$-octreotate) in our institution. Results of ${ }^{177} \mathrm{Lu}$ octreotate treatment in these patients are promising, with tumor size reduction in $47 \%$ of the treated patients [9].

Although infrequent, hormonal release-induced crises can occur after ${ }^{177} \mathrm{Lu}$-octreotate treatment. In this study, we describe all patients who developed a hormonal crisis in association with peptide receptor radionuclide therapy with ${ }^{177} \mathrm{Lu}$-octreotate.

\section{Materials and methods}

\section{Patients}

All patients with neuroendocrine tumors treated in our institution treated with ${ }^{177} \mathrm{Lu}$-octreotate between January 2000 and January 2007 were included in this study. All patients fulfilled the inclusion criteria for ${ }^{177} \mathrm{Lu}$-octreotate therapy [9]. All patients gave written informed consent to undergo ${ }^{177}$ Lu-octreotate therapy. This therapy was approved by the medical ethical committee of our hospital.

\section{Methods}

${ }^{177}$ Lu-octreotate was prepared as described previously [10].

Somatostatin analogue therapy was discontinued in 193 of 200 patients during ${ }^{177}$ Lu-octreotate therapy. Longacting somatostatin analogues (Sandostatin LAR, Lanreotide Autogel) were discontinued 1 month before therapy. Thereafter, therapy was switched to an immediate release somatostatin analogue (Octreotide) that was discontinued 1 day before ${ }^{177}$ Lu-octreotate therapy. An infusion of amino acids $(2.5 \%$ arginine, $2.5 \%$ lysine $1 \mathrm{l} / 4 \mathrm{~h})$ was administered to reduce the radiation dose to the kidneys, starting $30 \mathrm{~min}$ before administration of $7,400 \mathrm{MBq}{ }^{177}$ Lu-octreotate. Generally, four cycles of ${ }^{177} \mathrm{Lu}$-octreotate were given.

Routine hematology and liver and kidney function tests, as well as serum chromogranin A measurements (CgA), were performed before each therapy cycle in all patients. Additionally, 5-hydroxy-indole-acid (5HIAA) measurements in 24-h urine in the carcinoid patients, serum vasoactive intestinal peptide in the VIPoma patients, serum gastrin in gastrinoma patients, and excretion of normetanephrines and metanephrines in the 24-h urine in the patients with a metastatic pheochromocytoma were measured (laboratory normal values: $\mathrm{CgA}<100 \mu \mathrm{g} / 1,5 \mathrm{HIAA}<50 \mu \mathrm{mol} /$
$24 \mathrm{~h}$, VIP $25-65 \mathrm{pg} / \mathrm{ml}$, gastrin $<0.15 \mu \mathrm{g} / \mathrm{l}$, metanephrines $<$ $2 \mu \mathrm{mol} / 24 \mathrm{~h}$, normetanephrines $<5.1 \mu \mathrm{mol} / 24 \mathrm{~h}$ ).

\section{Results}

Patient characteristics

Four hundred seventy-nine patients with neuroendocrine tumors were studied: 262 men (55\%), and 217 women (45\%). Two hundred sixty-five patients $(53 \%)$ had metastatic carcinoid tumors: 52 patients $(11 \%)$ had metastatic neuroendocrine tumors of unknown origin, 124 patients $(26 \%)$ had non-functioning PNETs, 35 patients (7\%) had functioning PNETs, and 3 patients ( $1 \%$ ) had metastatic pheochromocytoma. The mean age at the time of the first therapy was 56 years (range, 16-85), and the mean Karnofsky performance score was 90 (range, 50-100). The tumor burden in the majority of the patients was high with liver metastases in $88 \%$ and bone metastases in $26 \%$ of the patients. Before ${ }^{177}$ Lu-octreotate therapy, $42 \%$ of patients were using somatostatin analogues to reduce hormonal symptoms. Patient characteristics are shown in Table 1.

Therapy and complications

The 479 patients received a total of 1,693 administrations of ${ }^{177}$ Lu-octreotate. Mild side effects within $24 \mathrm{~h}$ after ${ }^{177}$ Lu-octreotate therapy were nausea after $25 \%$, vomiting after $10 \%$, and increase of abdominal pain/discomfort after $9 \%$ of the treatment cycles.

After 10 of $1,691(0.6 \%)$ administrations of ${ }^{177} \mathrm{Lu}-$ octreotate in six patients $(1 \%)$, readmission or prolonged hospitalization because of hormonal release-induced crisis was necessary. Two of 20 patients with bronchial carcinoids, 2 of 3 patients with a VIPoma, 1 of 241 patients with a digestive tract carcinoid, and 1 of 3 patients with a pheochromocytoma had a crisis. All patients developing a crisis had extensive metastatic disease, all patients had liver metastases, and three also had skeletal metastases. Posttherapeutic scintigrams showing ${ }^{177}$ Lu-octreotate uptake in the metastases are shown in Fig. 1. Also, all patients had clinically overt hormonal-release-related symptomatology, like flushing and severe diarrhea. In two of these patients, hormonal symptoms were so severe that discontinuation of somatostatin analogue therapy before peptide receptor radionuclide therapy was impossible. Characteristics of these patients are shown in Table 2 . In all six patients, the hormonal crisis occurred during the first therapy cycle; three of the six patients developed the crisis during or directly after ${ }^{177} \mathrm{Lu}$-octreotate infusion, and the other three patients developed the crisis $48 \mathrm{~h}$ after ${ }^{177}$ Lu-octreotate infusion. 
Table 1 Patients' characteristics

\begin{tabular}{|c|c|c|c|c|c|c|}
\hline Tumor type & $\begin{array}{l}\text { Number of } \\
\text { patients }\end{array}$ & $\begin{array}{l}\text { Somatostatin analogue } \\
\text { pretreatment }\end{array}$ & $\begin{array}{l}\text { Liver } \\
\text { metastases }\end{array}$ & $\begin{array}{l}\text { Bone } \\
\text { metastases }\end{array}$ & $\begin{array}{l}\mathrm{CgA}(\mu \mathrm{g} / \mathrm{l}) \\
\text { median (range) }\end{array}$ & $\begin{array}{l}\text { Relevant laboratory findings } \\
\text { median (range) }\end{array}$ \\
\hline \multicolumn{7}{|l|}{ Carcinoids } \\
\hline $\begin{array}{l}\text {-Digestive tract } \\
\text { carcinoid }\end{array}$ & 241 & 142 & 223 & 57 & $\begin{array}{l}537 \\
(22-787,742)\end{array}$ & $\begin{array}{l}\text { Urinary 5HIAA }(\mu \mathrm{mol} / 24 \mathrm{~h}) \\
222(7-2,048)\end{array}$ \\
\hline -Bronchial carcinoid & 20 & 7 & 16 & 13 & $\begin{array}{l}1,252 \\
(35-900,280)\end{array}$ & $\begin{array}{l}\text { Urinary 5HIAA }(\mu \mathrm{mol} / 24 \mathrm{~h}) \\
191(15-1,440)\end{array}$ \\
\hline -Thymic carcinoid & 4 & 0 & 1 & 1 & $\begin{array}{l}294 \\
(147-725)\end{array}$ & - \\
\hline \multicolumn{7}{|l|}{ Functioning PNETs } \\
\hline -VIPoma & 3 & 0 & 3 & 9 & $\begin{array}{l}153 \\
(22-318)\end{array}$ & VIP (pg/ml) $470(144-710)$ \\
\hline -Insulinoma & 11 & 3 & 8 & 4 & $\begin{array}{l}1256 \\
(69-21,509)\end{array}$ & - \\
\hline -Gastrinoma & 21 & 8 & 19 & 5 & $\begin{array}{l}2,282 \\
(111-55,715)\end{array}$ & Gastrin $(\mu \mathrm{g} / 1) 1.2(0.03-22)$ \\
\hline $\begin{array}{l}\text { Non functioning } \\
\text { PNETs }\end{array}$ & 124 & 25 & 107 & 24 & $\begin{array}{l}385 \\
(26-162,710)\end{array}$ & - \\
\hline $\begin{array}{l}\text { Neuroendocrine } \\
\text { tumour } \\
\text { of unknown origin }\end{array}$ & 52 & 10 & 44 & 18 & $\begin{array}{l}400 \\
(23-29,110)\end{array}$ & - \\
\hline $\begin{array}{l}\text { metastatic } \\
\text { pheochromocytoma }\end{array}$ & 3 & 1 & 1 & 2 & $\begin{array}{l}5,666 \\
(928-6,900)\end{array}$ & - \\
\hline Total & 479 & $200(42 \%)$ & $422(88 \%)$ & $124(26 \%)$ & & \\
\hline
\end{tabular}

Digestive tract carcinoid (gastric, duodenum, short bowel, colon, and rectum carcinoids), PNETs (pancreas neuroendocrine tumors) laboratory normal values: $\mathrm{CgA}<100 \mu \mathrm{g} / \mathrm{l}, 5 \mathrm{HIAA}<50 \mu \mathrm{mol} / 24 \mathrm{~h}$, VIP $25-65 \mathrm{pg} / \mathrm{ml}$, gastrin $<0.15 \mu \mathrm{g} / \mathrm{l}$.

The treatment included high-dose octreotide, i.v. fluid replacement, and other supportive measures (as shown in Table 2); all patients fully recovered. In all six patients who developed a hormonal crisis after their first therapy cycle, additional precautions were taken before the administration of further therapy cycles, including continuation of somatostatin analogues, corticosteroids, prolonged observation in the hospital after therapy, and reduction of administered dosage of ${ }^{177}$ Lu-octreotate. Despite these precautions, three
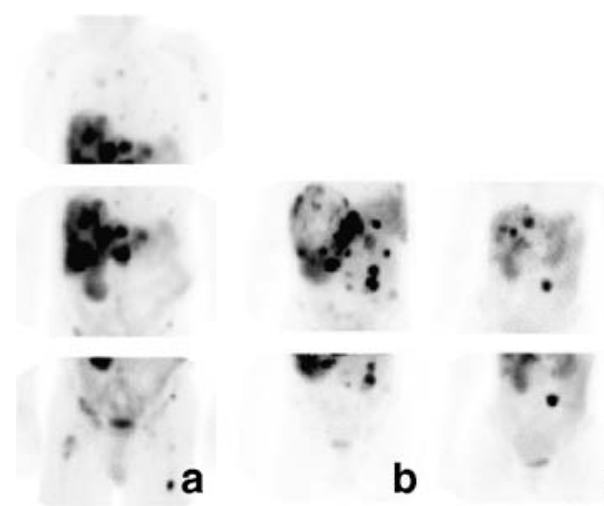

Fig. 1 Post-therapy scintigrams after ${ }^{177}$ Lu-octreotate of patient 1 (a), patient 2 (b), patient $3(\mathbf{c})$, patient 4 (d), patient 5 (e), and patient 6 (f). Upper row Anterior images of the thorax, middle row anterior images of the abdomen, and lower row anterior images of the pelvic region. patients developed a hormonal release-induced crisis again after a subsequent cycle of ${ }^{177}$ Lu-octreotate.

In two patients, hormonal release could be biochemically confirmed. We observed massive release of $\mathrm{CgA}$ in patient 1. CgA levels increased from 4,379 at baseline to $24,661 \mu \mathrm{g} / \mathrm{l}, 24 \mathrm{~h}$ after ${ }^{177} \mathrm{Lu}$-octreotate. Multiple urinary normetanephrines measurements were performed in patient 6; severely increased excretion of normetanephrines was observed shortly after therapy with ${ }^{177}$ Lu-octreotate (Fig. 2)

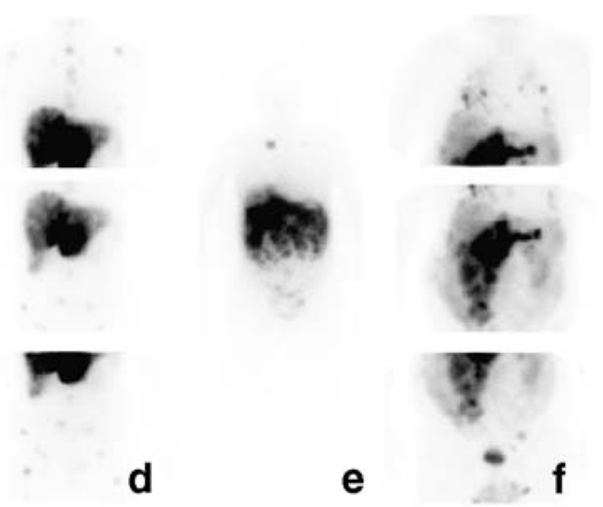

Note that the focal increased ${ }^{177} \mathrm{Lu}$-octreotate accumulations in liver metastases in all patients and focal uptake in bone metastases in patients 1,2 , and 4 . In patient 6 , there was also uptake in multiple lung metastases 


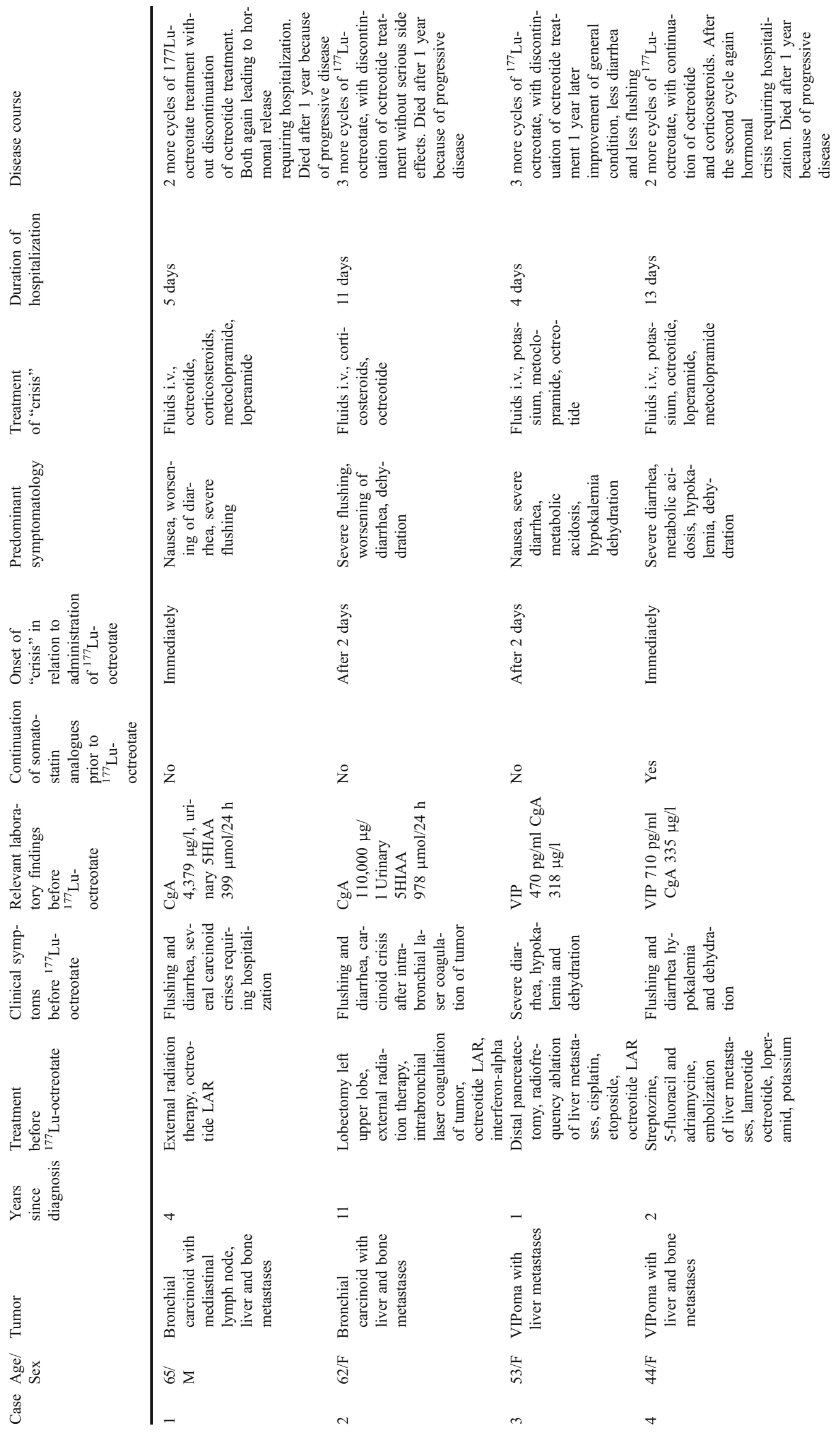



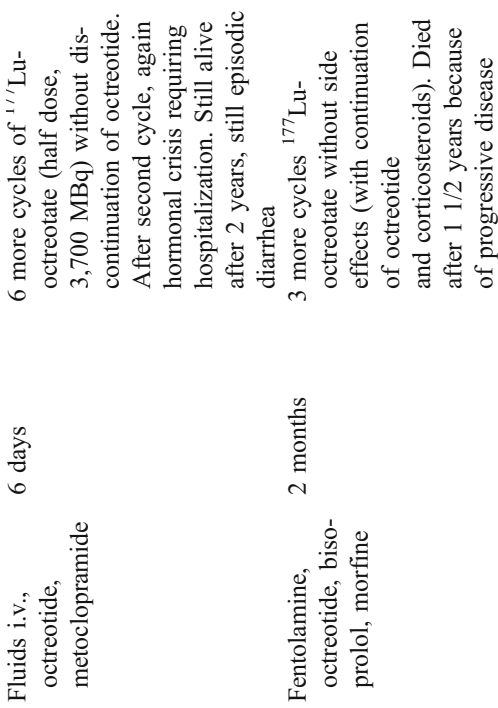

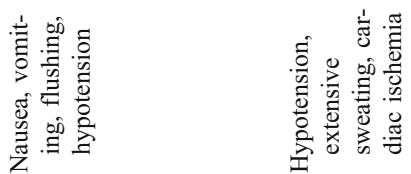

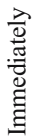

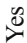

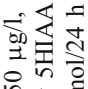

ํํำ

顿刍领

$\bar{\Xi}$

章

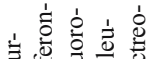

की

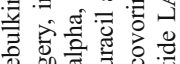

䓒

n

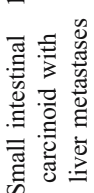

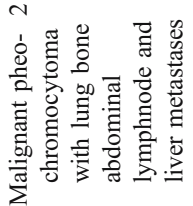

in $\Sigma$

ळু $\Sigma$
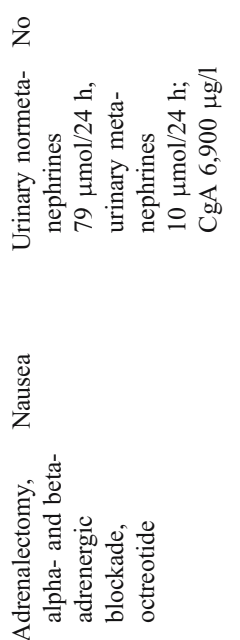

\section{Discussion}

Hormonal crises after ${ }^{177} \mathrm{Lu}$-octreotate therapy occur infrequently; only 6 of 479 patients with GEPNETs and malignant pheochromocytomas had a crisis. These patients all had preexisting clinically overt symptoms like flushing and diarrhea. All six patients had liver metastases, and three of six patients also had bone metastases. Patients who did not have a crisis after the first administration of ${ }^{177} \mathrm{Lu}-$ octreotate also did not develop a hormonal crisis after subsequent cycles.

In our series, two of three patients treated for metastatic VIPoma developed a hormonal crisis after ${ }^{177} \mathrm{Lu}$-octreotate. VIPomas are associated with a well-defined clinical syndrome characterized by severe watery diarrhea, hypokalemia, and metabolic acidosis (Verner-Morrison syndrome) [11]. Also, 2 of 20 patients treated for metastatic bronchial carcinoid developed a carcinoid crisis. The carcinoid syndrome in patients with metastatic bronchial carcinoids is mediated by 5-hydroxytryptophan, its conversion to serotonin and/or by histamine[12]. The only other documented carcinoid crisis after radionuclide receptor therapy also involved a patient with a bronchial carcinoid [7]. Only one of the 241 patients with a carcinoid originating from the digestive tract had a hormonal crisis.

One of the three patients treated for a metastatic pheochromocytoma developed a pheochromocytoma crisis. Hormonal crises in pheochromocytoma patients because of massive release of catecholamines can lead to multiple clinical features including (episodic) hypertension or hypotension, myocardial

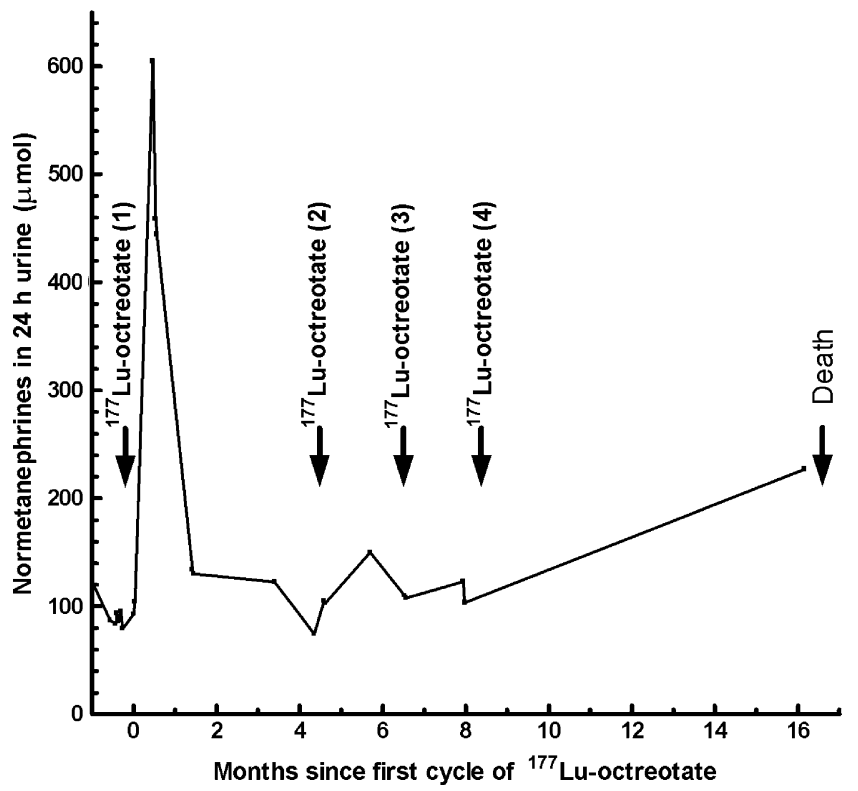

Fig. 2 Normetanephrines in $24 \mathrm{~h}$ urine $(\mu \mathrm{mol})$ of patient 6 after ${ }^{177} \mathrm{Lu}$-octreotate treatment. Note the excessive release of normetanephrines after the first cycle of ${ }^{177} \mathrm{Lu}$-octreotate. Normal value urinary normetanephrines: $<5.1 \mu \mathrm{mol} / 24 \mathrm{~h}$ 
ischemia, cardiomyopathia, pulmonary edema, and shock $[13,14]$. After ${ }^{131}$ I-MIBG therapy, excessive catecholamine secretion with the above-mentioned severe symptomatology has been reported $[15,16]$.

No serious hormonal release-induced side effects were observed in patients with other tumors; there were no episodes of severe hypoglycemia in patients with metastatic insulinoma, and none of the patients with metastatic gastrinoma, non-functioning GEPNETs, or neuroendocrine tumors of unknown origin developed a hormonal crisis after ${ }^{177}$ Lu-octreotate.

The exact mechanism of increased hormonal release in the patients developing a hormonal crisis after ${ }^{177} \mathrm{Lu}-$ octreotate is not fully elucidated. Several mechanisms may have accounted for the induction of such a crisis in our patients: (1) tumor lysis because of beta-irradiation from ${ }^{177} \mathrm{Lu}$, (2) discontinuation of short-acting somatostatin analogues before ${ }^{177} \mathrm{Lu}$-octreotate administration, (3) emotional stress response to hospitalization and/or therapy, or (4) administration of amino acids (2.5\% arginine and $2.5 \%$ lysine). These amino acids might be used as substrates for increased hormone synthesis by the tumor cells.

Arguments for tumor lysis because of beta irradiation are the relatively late onset of complaints ( $>24 \mathrm{~h}$ after therapy) in patients 2, 3, and 6. Patients 1, 4, and 5 had direct onset of complaints during ${ }^{177} \mathrm{Lu}$-octreotate infusion; these crises cannot be explained by tumor lysis. In patients 4 and 5, the hormonal crisis might have been induced by emotional stress in combination with amino acid infusion. These patients continued their somatostatin analogue therapy. It is well known that emotional stress can provoke flushing [17]; therefore, it might also be possible that emotional distress, present in carcinoid patients [18], might have played a role in the development of the hormonal crises in these patients. In patient 1 , the hormonal crisis might also be related to discontinuation of somatostatin analogue therapy. When possible, we stop somatostatin analogues before ${ }^{177} \mathrm{Lu}$ octreotate therapy to prevent competitive binding to the somatostatin receptors with ${ }^{177} \mathrm{Lu}$-octreotate. The basis for this approach is the finding of a decreased ${ }^{111}$ In-octreotide uptake by the tumor (although not significant) in patients continuing somatostatin analogue treatment compared to patients discontinuing somatostatin analogue treatment [19].

Direct receptor-mediated hormonal release by ${ }^{177} \mathrm{Lu}-$ octreotate seems unlikely. Somatostatin receptor binding leads to decrease in hormonal secretion in the majority of patients. Therapy with somatostatin analogues in patients with metastatic carcinoid tumors results in symptomatic improvement in more than $70 \%$ of the patients and biochemical response in 50 to $60 \%$ of the patients [20, 21].

All patients received further cycles of ${ }^{177} \mathrm{Lu}$-octreotate after their first hormonal crisis. When re-treating these patients, continuation of somatostatin analogues in combi- nation with corticosteroids is indicated [22, 23]. In one patient, we halved the administered activity to $3,700 \mathrm{MBq}$ ${ }^{177} \mathrm{Lu}$-octreotate to decrease potential tumor lysis because of beta irradiation. Of course, important drawback of such a treatment protocol is that the tumor-absorbed radiation dose will also be decreased.

Recommended treatment of patients with hormonal crises are high-dose somatostatin analogues i.v., i.v. fluids, corticosteroids, and correction of electrolyte disturbances in patients with diarrhea and vomiting. Patients with metastatic pheochromocytoma should also be treated with alphaand beta-adrenergic blockade. From the present experience, we also recommend continuation of somatostatin analogue therapy in patients with metastatic VIPomas and bronchial carcinoids who have symptomatology of (atypical) carcinoid syndrome.

\section{Conclusion}

Hormonal crises after ${ }^{177} \mathrm{Lu}$-octreotate occur infrequently. In our series, only 6 of 479 patients had such a crisis. Patients treated for VIPoma or bronchial carcinoids are most at risk. All patients with a hormonal crisis eventually recovered. Other less serious side effects shortly after ${ }^{177} \mathrm{Lu}$-octreotate, such as nausea, vomiting, and abdominal pain, are more common and can be controlled by supportive measures. Generally, ${ }^{177} \mathrm{Lu}$-octreotate therapy is well tolerated.

Open Access This article is distributed under the terms of the Creative Commons Attribution Noncommercial License which permits any noncommercial use, distribution, and reproduction in any medium, provided the original author(s) and source are credited.

\section{References}

1. Karmy-Jones R, Vallieres E. Carcinoid crisis after biopsy of a bronchial carcinoid. Ann Thorac Surg. 1993;56:1403-5.

2. Kharrat HA, Taubin H. Carcinoid crisis induced by external manipulation of liver metastasis. J Clin Gastroenterol. 2003;36:87-8.

3. Ozgen A, Demirkazik FB, Arat A, Arat AR. Carcinoid crisis provoked by mammographic compression of metastatic carcinoid tumour of the breast. Clin Radiol. 2001;56:250-1.

4. Vaughan DJA, Brunner MD. Anesthesia for patients with carcinoid syndrome. Int Anesthesiol Clin. 1997;35:129-42.

5. Salm EF, Janssen M, Breburda CS, van Woerkens LJPM, de Herder WW, Zwaan Cvd, et al. Carcinoid crisis during transesophageal echocardiography. Intensive Care Med. 2000;26:254-54.

6. Lips CJ, Lentjes EG, Hoppener JW. The spectrum of carcinoid tumours and carcinoid syndromes. Ann Clin Biochem. 2003;40: 612-27.

7. Davi MV, Bodei L, Francia G, Bartolomei M, Oliani C, Scilanga $\mathrm{L}$, et al. Carcinoid crisis induced by receptor radionuclide therapy with 90Y-DOTATOC in a case of liver metastases from bronchial neuroendocrine tumor (atypical carcinoid). J Endocrinol Invest. 2006;29:563-7. 
8. Kaltsas GA, Papadogias D, Grossman AB. The clinical presentation (symptoms and signs) of sporadic and familial chromaffin cell tumours (phaeochromocytomas and paragangliomas). Front Horm Res. 2004;31:61-75.

9. Kwekkeboom DJ, Teunissen JJ, Bakker WH, Kooij PP, de Herder WW, Feelders RA, et al. Radiolabeled somatostatin analog [177Lu-DOTA0,Tyr3]octreotate in patients with endocrine gastroenteropancreatic tumors. J Clin Oncol. 2005;23:2754-62.

10. Kwekkeboom DJ, Bakker WH, Kooij PP, Konijnenberg MW, Srinivasan A, Erion JL, et al. [177Lu-DOTAOTyr3]octreotate: comparison with [111In-DTPAo]octreotide in patients. Eur J Nucl Med. 2001;28:1319-25.

11. Bloom SR, Yiangou Y, Polak JM. Vasoactive intestinal peptide secreting tumors. Pathophysiological and clinical correlations. Ann N Y Acad Sci. 1988;527:518-27.

12. Caplin ME, Buscombe JR, Hilson AJ, Jones AL, Watkinson AF, Burroughs AK. Carcinoid tumour. Lancet. 1998;352:799-805.

13. Kizer JR, Koniaris LS, Edelman JD, St. John Sutton MG. Pheochromocytoma crisis, cardiomyopathy, and hemodynamic collapse. Chest. 2000;118:1221-3.

14. Werbel SS, Ober KP. Pheochromocytoma. Update on diagnosis, localization, and management. Med Clin North Am. 1995;79:131-53.

15. Sasaki M, Iwaoka T, Yamauchi J, Tokunaga H, Naomi S, Inoue J, et al. A case of Sipple's syndrome with malignant pheochromocytoma treated with 131I-metaiodobenzyl guanidine and a combined chemotherapy with cyclophosphamide, vincristine and dacarbazine. Endocr J. 1994;41:155-60.
16. Safford SD, Coleman RE, Gockerman JP, Moore J, Feldman JM, Leight GS, et al. Iodine-131 metaiodobenzylguanidine is an effective treatment for malignant pheochromocytoma and paraganglioma. Surgery 2003;134:956-62.

17. Bell HK, Poston GJ, Vora J, Wilson NJ. Cutaneous manifestations of the malignant carcinoid syndrome. $\mathrm{Br} \mathrm{J}$ Dermatol. 2005;152:71-5.

18. Frojd C, Larsson G, Lampic C, von Essen L. Health related quality of life and psychosocial function among patients with carcinoid tumours. A longitudinal, prospective, and comparative study. Health Qual Life Outcomes. 2007;5:18.

19. Rolleman EJ, Kooij PP, de Herder WW, Valkema R, Krenning EP, de Jong M. Somatostatin receptor subtype 2-mediated uptake of radiolabelled somatostatin analogues in the human kidney. Eur $\mathrm{J}$ Nucl Med Mol Imaging 2007;34(11):1854-60.

20. de Herder WW, Lamberts SW. Somatostatin and somatostatin analogues: diagnostic and therapeutic uses. Curr Opin Oncol. 2002;14:53-7.

21. Oberg K, Kvols L, Caplin M, Delle Fave G, de Herder W, Rindi $\mathrm{G}$, et al. Consensus report on the use of somatostatin analogs for the management of neuroendocrine tumors of the gastroenteropancreatic system. Ann Oncol. 2004;15:966-73.

22. Kvols LK, Martin JK, Marsh HM, Moertel CG. Rapid reversal of carcinoid crisis with a somatostatin analogue. N Engl J Med. 1985;313:1229-30.

23. Warner RR, Mani S, Profeta J, Grunstein E. Octreotide treatment of carcinoid hypertensive crisis. Mt Sinai J Med. 1994;61:349-55. 